This item was submitted to Loughborough's Research Repository by the author.

Items in Figshare are protected by copyright, with all rights reserved, unless otherwise indicated.

\title{
Closed Loop Supply Chain (CLSC): economics, modelling, management and control
}

PLEASE CITE THE PUBLISHED VERSION

http://dx.doi.org/10.1016/j.ijpe.2016.11.020

PUBLISHER

(C) Elsevier

VERSION

AM (Accepted Manuscript)

\section{PUBLISHER STATEMENT}

This work is made available according to the conditions of the Creative Commons Attribution-NonCommercialNoDerivatives 4.0 International (CC BY-NC-ND 4.0) licence. Full details of this licence are available at: https://creativecommons.org/licenses/by-nc-nd/4.0/

\section{LICENCE}

CC BY-NC-ND 4.0

\section{REPOSITORY RECORD}

Battini, Daria, Marija Bogataj, and Alok K. Choudhary. 2019. "Closed Loop Supply Chain (CLSC): Economics, Modelling, Management and Control”. figshare. https://hdl.handle.net/2134/24126. 


\title{
Closed Loop Supply Chain (CLSC): Economics, Modelling, Management and Control
}

\author{
Daria Battini $^{\mathrm{a}}$, Marija Bogataj ${ }^{\mathrm{b}}$, Alok Choudhary ${ }^{\mathrm{c}}$ \\ ${ }^{a}$ Department of Management and Engineering - University of Padova, Stradella San Nicola \\ 3, 36100 Vicenza, Italy. Email: daria.battini@unipd.it \\ ${ }^{\mathrm{b}}$ MEDIFAS, Mednarodni prehod 6, Vrtojba, Sempeter pri Gorici, Slovenia. Email: \\ marija.bogataj@guest.arnes.si \\ ${ }^{c}$ School of Business and Economics, Loughborough University, Loughborough, United \\ Kingdom. Email: a.choudhary@,lboro.ac.uk
}

\begin{abstract}
This article summarizes the papers published in the special issue entitled "Closed Loop Supply Chain (CLSC): Economics, Modelling, Management and Control" in the International Journal of Production Economics. A total of 24 papers, covering an extensive range of topics in the Closed Loop Supply Chain research area, have been included in this special issue. This special issue received a wide and diverse geographical contribution with authors from 16 countries located in 4 continents including America, Asia, Europe, and Africa. Initially, the special issue received 71 research paper submissions and the final selection of 24 papers, which were recommended by at least two reviewers, provide a basis for new research directions in the domain of reverse logistics and closed loop supply chain management.
\end{abstract}

Keywords: Closed Loop Supply Chain, Reverse Logistics, Modelling, Supply Chain Management.

\section{Introduction}

In the last decade, Closed-Loop Supply Chains (CLSC) and Reverse Logistics (RL) have attracted increasing attention in supply chain and operations management research. This attention has been also motivated by different governmental actions around the world devoted to force manufacturing companies and retailers in managing their End of Life products (Govindan et al., 2015). CLSCs couple the conventional forward supply chain processes with 
reverse logistics processes, which range from product recovery, product remanufacturing, disassembly and part reusing (Kumar and Putnam, 2008; Östlin et al., 2008; Guide and Van Wassenhove, 2009). The final aim is to capture values of products being consumed and used by customers with the possibility to reduce the environmental impact on the whole supply chain. In general, a more complex system is obtained by closing the loop of the supply chain in comparison to the traditional linear supply chain. For instance, complexity arises in managing materials inventories, return flows and transportation at different states, in planning the level of service orientation of resources, in managing manufacturing and remanufacturing at the same time in the same production facilities, and in coordinating the network as a whole. Moreover, planning and controlling operations in this environment become more complex due to uncertainties in the information flows regarding return processes and the associated difficulties of the interface coordination between return flows and conventional forward flows. Moreover, the CLSC management topic responds to EU research priorities identified in the recent Horizon 2020 programme that stresses the need for increased product life-spans, material reuse, recycling, resource recovery, and industrial symbiosis leading to closed-loop processes.

The present special issue presents a set of novel research in quantitative methods and models specifically developed to help managers and practitioners in creating more efficient, lower cost, and sustainable closed loop supply chain systems.

We classified the 24 papers presented in this Special Issue into six groups:

1. Production planning of hybrid manufacturing/remanufacturing systems (6 papers)

2. CLSC coordination problems with environmental measures and multi-objective optimization (6 papers) 
3. Closed loop network design problems under specific dynamic and stochastic aspects (4 papers)

4. Profit models for CLSC under different scenarios (4 papers)

5. Returnable Transport Items (RTI) analysis and optimization (2 papers)

6. Resource Recovery (2 papers)

\section{Production planning of hybrid manufacturing/remanufacturing systems}

In the first group of papers, Polotski et al. address the production planning of hybrid manufacturing/remanufacturing systems from a manufacturing plant point of view. The authors present an analytical solution for optimal production and setup schedule along the production cycles, considering the case of reliable and unreliable manufacturing systems.

Habibi et al. develop an integrated mathematical model focused on the End-of-Life product collection and disassembly process. The model incorporates operational decisions of the vehicle routing problem by considering a set of disassembly factors linked to End-of-Life products.

Navin et al. study inventory and production planning problem in a closed-loop system while considering both manufacturing and remanufacturing. They investigate five inventory and production planning models under the continuous and periodic review systems using a discrete event simulation. The authors considered different demand and return rates in addition to the manufacturing and remanufacturing lead times.

Production planning and control of remanufacturing systems often lies in the inability to accurately forecast core returns. This problem is discussed by Kumar et al. by developing a range of hazard rate models for core returns duration modelling. The models are also validated by using data from a large global automotive supplier. 
Hariga et al. consider a centralized CLSC comprised of a single vendor and a single buyer operating under a consignment stock (CS) strategy. They develop a mixed integer non-linear program that seeks to minimize the chain-wide total cost by jointly optimizing the length of the production cycle, the number and the sequence of the newly manufactured and the remanufactured batches, as well as the inventory levels of the finished and recovered products at the beginning of the cycle. The last paper of this first group by Wang and Gunasekaran, formulates the scheduling problem as a bi-criteria mixed integer program with the objective of minimizing total shipping and penalty costs and delivery lateness in a remanufacturing context.

\section{CLSC coordination problems with environmental measures and multi-objective optimization}

The first paper in this group, by Kadambala et al., provides a new multi-objective mixed integer linear programming model to evaluate delay parameters by maximizing profit, optimizing customer surplus, and minimizing energy use. They argue that the decision makers may achieve an optimal trade-off among the differing objectives in a multipleobjective CLSC scenario. Bazan et al. focus on a two-level CLSC with a manufacturer and a retailer with a facility to remanufacture used items. They consider three critical environmental issues: the energy used in production (manufacturing and remanufacturing) processes, GHG emissions from production and transportation activities, and the number of times to remanufacture (recover) a used item. Banasik et al. propose a multi-objective mixed integer linear programming model to quantify trade-offs between economic and environmental indicators and explore quantitatively alternative recycling technologies. A multi-objective optimization mathematical model to minimize overall costs and carbon dioxide emissions when setting the supply chain is developed by Nurjanni et al. The model is tested in a case study in order to investigate the trade-off between costs and environmental 
issues. $\mathrm{Xu}$ et al. investigate the supply chain coordination problem under Cap-and-Trade Regulation and finally demonstrate that firms can cooperate to reduce carbon emission without affecting their profits. Finally, Nasir et al. use a case study from the construction industry to demonstrate the environmental gains in terms of carbon emissions that can be achieved through some circular economy principles as against traditional linear production systems.

\section{Closed loop network design problems under specific dynamic and stochastic aspects}

Kumar et al. contribute to the limited literature on reverse logistics that considers costs and profit as well as vehicle route management. The objective of their paper is to maximize the total expected profit and also to obtain an efficient route for the vehicle. The network considered in the model assumes a fixed number of suppliers, facilities, distributors, customer zones, disassembly locations, re-distributors, and second customer zones.

Jeihoonian et al. consider a CLSC network design problem in the context of modular structured products in which the reverse network involves several types of recovery options. It accounts for uncertainty in the quality status of the return flows.

Zhou et al. investigate a three-echelon manufacturing and remanufacturing closed-loop network constituting of a retailer, a manufacturer and a supplier. Their model is based on the Automated Pipeline, Inventory and Order Based Production Control System (APIOBPCS) in order to investigate the bullwhip effect and inventory variance from one echelon to the next.

Finally, Ivanov et al. consider the return flows in the SC under a different point of view: undesired return material flows can also occur after a disruptive event in SC. The authors apply a hybrid linear programming-system dynamics model that allow simultaneously recomputing the material flows in a multi-stage SC after a disruption and comparing the performance impact of different recovery policies subject to variable recovery costs and time. 


\section{Profit models for CLSC under different scenarios}

When the consumers wish to capitalize the products residual value, they should return them as early as possible. Accordingly, Genc and De Giovanni develop a model of a CLSC, in which consumers seek to gain as much as possible from their returns and the return rate is a function of both price and quality. Xie et al. study contract coordination of centralized and decentralized dual-channel CLSCs by considering the relationship between the recycle rate and the recycle revenue sharing ratio. Chen extends the imperfect manufacturing problem by investigating the combined effects of a pricing scheme, replenishment program, imperfect quality, and the rework process for deteriorating items. The key to fully achieve the benefits of remanufacturing lies in the efficient and cost-effective reuse of components from end-oflife products. Wang et al. model the economic benefits of component reuse in the remanufacturing supply chain. They examine how product diffusion dynamics in the market affect the volume of the components reused in the single-generation life cycle of a product.

\section{Returnable Transport Items (RTI) analysis and optimization}

An RTI CLSC is a supply chain, in which returnable transport items (RTIs) are used for shipping products along the different stages of the chain. in this group of papers, the research focus is on the return of RTIs instead on the return of the finished products. Once a loaded RTI reaches the recipient $(\mathrm{R})$, it is emptied and sent back to the sender (S). If necessary, RTIs could be cleaned, repaired, or replaced, either at the sender or the recipient. Two papers are included in this group. The first one by Glock reports the results of a systematic literature review of decision support models for the management of CLSCs involving RTIs. The second paper by Iassinovskaia et al. address a pickup and delivery inventory-routing problem with RTIs considering time windows over a planning horizon. 


\section{Resource Recovery}

In the last group of papers, the focus is shifted to the Waste-to-Energy (WTE) problem. WTE policies can significantly reduce the volume of waste disposed to landfills, influence the reduction of total greenhouse gas emissions, and give the potential for generating electricity or developing co-generation of electricity and heat. Alternatively, waste items can be reversibly used as a source of energy with several technological methods. Kovačić et al. develop a model, which supports decisions on investments in urban cogeneration plants. Their model considers the simultaneous uncertainty of demand and uncertain efficiency of the plant. Finally, Russo and Sgarbossa focus on the food supply chain by developing a proactive model to analyse resource recovery during the entire production process in the meat industry.

\section{References}

Kumar S., Putnam V., 2008, Cradle to cradle: Reverse logistics strategies and opportunities across three industry sectors, International Journal of Production Economics - INT J PROD ECON, vol. 115, no. 2, pp. 305-315.

Govindan K., Soleimani H., Kannan D., 2015, Reverse logistics and closed-loop supply chain: A comprehensive review to explore the future. European Journal of Operational Research, vol. 240, pp. 603-626.

Guide Jr. V.D.R., Van Wassenhove L.N., 2009, The Evolution of closed-loop supply chain research, Operations Research, Vol. 57 Issue 1, pp. 10-18.

Östlin, J., Sundin, E., Björkman, M., 2008, Importance of closed-loop supply chain relationships for product remanufacturing. International Journal of Production Economics, vol. 115, no. 2, pp. 336-348. 